\title{
Region vector - программное обеспечение для анализа активности населения в аграрном секторе экономики
}

\author{
Л. И. Попкова ${ }^{1}$, А. С. Овсянников ${ }^{2}$ \\ ${ }^{1}$ Курский государственный университет, Российская Федераџия \\ (305000, г. Курск, ул. Радищева, 33) \\ ${ }^{2} О О О$ «ППФ Страхование Жизни», Российская Федерачия \\ (394038, г. Воронеж, ул. Космонавтов, 17A)
}

\begin{abstract}
Аннотация: Цель: на основе методов математической статистики создать информационное обеспечение, которое будет показывать векторы развития систем сельского расселения регионов и муниципальных районов в аграрном секторе экономики.

Информационной базой служили материалы территориальных органов федеральной службы государственной статистики Белгородской, Воронежской, Курской, Липецкой, Тамбовской областей.

Meтодbl. Цель работы достигнута с применением методов корреляционно-регрессионного анализа. Было сделано моделирование векторов развития (теоретических линий регрессии) каждого региона в прямоугольной системе координат. Применение пространственно-координатного анализа объектов исследования дало возможность визуально по углу наклона траекторий сравнивать направленность развития областей в аграрном секторе экономики, а также определить отстающие по производительности труда муниципалитеты.

Результаты и обсуждение. Выполнена количественная и визуальная оценка изменений в направленности развития сельхозпредприятий областей Центрального Черноземья за 2009-2014 годы. На этой основе создана компьютерная программа, которая позволяет объективно оценивать траектории развития сельхозпредприятий, фермерских хозяйств и хозяйств населения регионов.

Bblвoдbl. Применение компьютерной программы и пространственно-координатного анализа объектов исследования (моделей) даст преимущество органам управления всех уровней при оценке ситуации и реагировании на негативные изменения в производительности труда муниципалитетов в аграрном секторе экономики.
\end{abstract}

Ключевые слова: регион, занятое население, муниципалитеты, корреляционно-регрессионный анализ, пространственно-координатный анализ, $\alpha$ вектора развития.

Для цитирования: Попкова Л.И., Овсянников А.С. Region vector - программное обеспечение для анализа активности населения в аграрном секторе экономики // Вестник Воронежского государственного университета. Серия: География. Геоэкология, 2021, № 1, c. 3-13. DOI: https://doi.org/10.17308/geo.2021.1/3251

\section{ВВЕДЕНИЕ}

Постоянно меняющиеся условия развития экономики сельских территорий приводят к снижению численности населения. Несмотря на рост объемов производства произошло снижение численности занятых на сельхозпредприятиях. В сложившейся ситуации сохранение сельского населения и его присутствие в отдалённых от региональных центров муниципальных районах во многом будет зависеть от возможностей произ- водства товарной продукции в малых и средних хозяйствах. В этой связи необходимо создание информационных технологий для анализа состояния и направленности развития форм аграрного сектора экономики регионов: сельхозпредприятий, крестьянских (фермерских) хозяйств, хозяйств населения. Это возможно на основе методов математического моделирования.

Существует множество направлений моделирования систем сельского расселения с при-

(C) Попкова Л.И., Овсянников А.С., 2021

$\triangle$ Овсянников Артем Сергеевич, e-mail: artem_ovsyannikov@list.ru 
менением методов математической статистики: разработка прогнозов перехода от одной территориальной структуры населенных пунктов к другой [1]; определение потенциалов поля расселения, включая демографическую ёмкость территории [4]; разработка многофакторных моделей социального развития на основе уравнений множественной регрессии [2]; мониторинг и прогнозирование трудовой активности в различных секторах экономики, включая частный [6].

А. М. Носонов отмечает, что особенно важно в географических исследованиях практически применить класс линейных моделей, которые наиболее удобны для анализа и вычислений. Такие конструкции относятся к динамическим статистическим моделям, позволяющим оценивать развитие геосистем и прогнозировать их состояние [5]. Мы считаем, что особенностью географического подхода изучения моделей процессов на территориях одного уровня управления должно быть не только сравнение параметров уравнений, но и визуальная оценка распределений точек рассеяния, направлений теоретических линий регрессии.

Большинство линейных регрессионных моделей, где оценивается зависимость объемов производства аграрного сектора от численности занятого населения условно можно отнести к двум типам.

1. Временные экономико-математические модели, оценивающие изменения взаимосвязанных показателей конкретной территории (муниципального района, региона, федерального округа) за многолетний период, используются для анализа прошлого состояния и прогнозирования развития. Базы исходных данных таких моделей не включают информацию по единицам административно-территориального деления внутри границ анализируемого объекта (региона) и поэтому не способны оценивать внутрирегиональные различия.

2. Территориальные экономико-математические модели, структура баз исходных данных которых представляет собой показатели единиц административно-территориального деления или других объектов (предприятий, объектов торговли) в границах конкретной территории (муниципального района, региона, групп регионов) за определенный год, квартал, месяц. В то же время полученную информацию сложно сопоставить с другими территориями, поскольку для них требуется сбор таких же данных и разработка аналогичной модели, а полученные результаты быстро устаревают, что требует их постоянного обновления [8].
Примером первого типа моделей служит многофакторная корреляционно-регрессионная модель анализа сельскохозяйственного производства Приморского края Е. М. Дроздовой, где оценивается зависимость объемов производства сельского хозяйства в сопоставимых ценах за период 2005 - 2011 годов от таких показателей как количество занятых, производительность труда (выработка), посевная площадь, урожайность, объем используемых основных фондов, фондоотдача [3]. Эта модель в определенной мере объясняет степень влияния некоторых факторов, но обладает рядом недостатков: результат применения относится лишь к одному региону; объем производства всего сельского хозяйства в сопоставимых ценах при изменении структуры производства не позволяет объективно оценивать состояние и развитие сельских территорий, которое зависит от деятельности различных организационно-правовых форм аграрного сектора экономики.

Примером второго типа моделей является корреляционно-регрессионная модель, оценивающая зависимость объема выпуска сельхозпродукции от различных факторов на территориях Центрального и Северо-Западных Федеральных округов разработанная Л.В. Пронченко [9]. Ее отличает структура исходных данных, которая представляет собой несколько равнозначных по уровню управления объектов (регионов) и привязанных к ним показателей за конкретный год (семь факторных признаков и один результативный показатель - объем произведенной продукции сельского хозяйства, млн. руб.). Следует отметить, что результат применения представленной модели относится лишь к определенному году, в то время как условия развития постоянно меняются, что требует регулярного обновления исходных данных. Кроме того, на уровне конкретной области использовать модель, где показатели охватывают территорию площадью 2,3 млн. кв. км невозможно.

Попытка сопоставить результаты моделирования на основе регрессионного анализа в прямоугольной системе координат представлена в работе И.В. Филимоненко [10]. Построенные регрессионные модели оценивают тесноту взаимосвязи изменения внутреннего валового продукта (ВВП) от численности занятых в экономике с учетом уровня образования. Вместе с тем сравнить полученные результаты на диаграммах рассеяния сложно поскольку параметры результативного признака остаются одинаковыми, меняются значения только факторных признаков (численность занятых, 
тыс. чел.). Кроме того, шкалы интервалов вариационных рядов по оси $\mathrm{X}$ разные и поэтому не позволяют достаточно точно сравнивать распределения точек рассеяния и направление теоретической линии регрессии.

Несмотря на отсутствие возможности учета территориальных различий, имеет значение разграничение факторного признака (численность занятых, тыс. чел.) по уровню образования. Вместе с тем такое же действие необходимо выполнить и с результативным показателем (ВВП, трлн. руб.). Это даст возможность более точно отразить роль уровня образования на формирование ВВП для каждой группы занятого населения.

Таким образом практическое применение выше указанных разработок в качестве алгоритмов для программного обеспечения не было обнаружено по нескольким причинам: 1) применение моделей ограничивалось временными рамками, в которые ставились задачи исследования; 2) моделирование не учитывает стратифицирующий фактор самой территории, когда охват групп регионов в разных федеральных округах в одной модели не позволяет объективно применять конечные результаты для конкретных областей, которые в силу различных условий формируют свои модели развития; 3) отсутствие в официальной статистике необходимых исходных данных в разрезе муниципалитетов, что является препятствием для подготовки аналогичных моделей на региональном уровне управления; 4) акцент на оценку факторов формирования объема про- изведенной продукции всего аграрного сектора, в то время как сельхозпредприятия, крестьянские (фермерские) хозяйства и личные подсобные хозяйства имеют разные стартовые условия развития; 5) сложности восприятия многофакторных регрессионных моделей при их применении в различных частях страны и отображения нескольких факторов в прямоугольной системе координат; 6) в результате этого технически не была применена возможность визуального представления территориальных объектов (муниципалитетов) каждого региона в информационном поле соответствующей прямоугольной системы координат, что дает возможность их сравнивать по распределению точек рассеяния (муниципалитетов) и направлению теоретической линии регрессии; 7) сложности в обновлении исходных данных для актуальности применения моделей, что требует вложения средств на регулярное проведение исследований с привлечением ряда специалистов, занимающихся сбором, обработкой и интерпретацией результатов, либо поиска других путей решения, где большинство операций выполняется автоматически.

Развитие информационных технологий привело к тому, что в экономических науках, и социально-экономической географии, в частности, применяется многофакторное моделирование, где, в том числе, оценивается зависимость объемов произведенной продукции аграрного сектора экономики от различных показателей, включая численность работников. Вместе с тем идеи
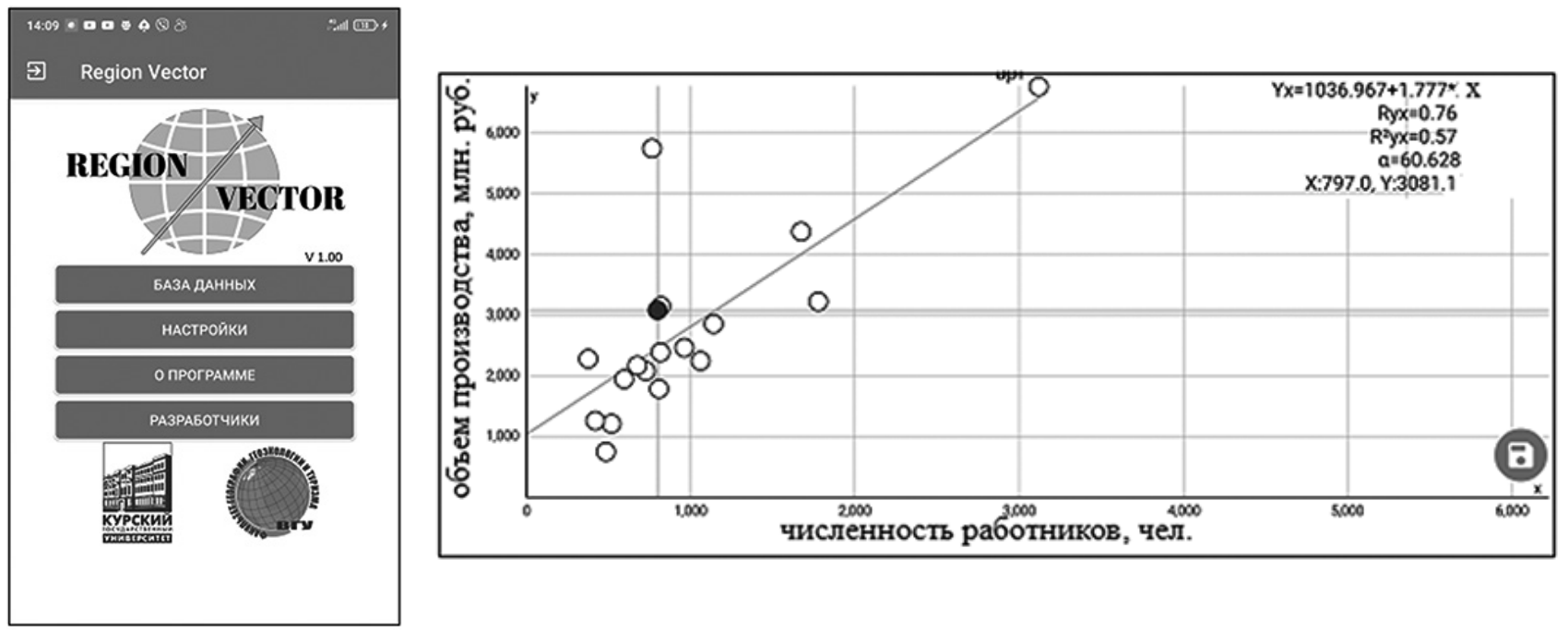

Puc.1. Стартовое меню, информационное поле прямоугольной системы координат в программе Region Vector и вектор активности населения на сельхозпредприятиях муниципальных районов Липецкой области в 2014 году

[Fig. 1. Start menu, information field of the rectangular coordinate system in the Region Vector program and the vector of population activity in agricultural enterprises of municipal districts of the Lipetsk region in 2014]

Вестник ВГУ, Серия: География. Геоэкология, 2021, № 1, 3-13 
встроить статистическую модель в целевое программное обеспечение (рис. 1), где выполняется визуальная оценка геоданных активности сельского населения регионов с применением регрессионного анализа в прямоугольной системе координат, не появилось. Одной из причин этого является акцент на построение многофакторных моделей, для которых иногда невозможно построить диаграммы рассеяния. Таким образом, аналогов представленного программного обеспечения не найдено из-за отсутствия идеи визуального сравнения распределений точек рассеяния и направлений теоретических линий регрессии по различным территориям одного уровня управления (регионам) в отдельности.

Целью разработки программного обеспечения (ПО) Region Vector является совершенствование мониторинга агропромышленных регионов на основе способа визуализации векторов развития форм аграрного сектора экономики. Задачей ПО является сокращение времени на поиск муниципалитетов, для которых в первую очередь необходимо принятие управленческих решений по диверсификации и оптимизации сельхозпроизводства. Технический результат применения алгоритма ПО обеспечивает отображение муниципалитетов и векторов развития регионов в конкретной форме аграрного сектора экономики таким образом, который позволяет сравнивать их между собой в прямоугольной системе координат.

\section{МЕТОДЫ ИССЛЕДОВАНИЯ}

ПО осуществляет последовательность действий на основе методов математической статистики по территории нескольких регионов одновременно и является пространственно-временной экономико-географической моделью, которая работает в устройствах на базе ОС Android. В peзультате появилась возможность быстрого сравнения векторов развития (теоретических линий регрессии) различных территорий по углу наклона $\alpha$ относительно оси X (рис. 2). Для расчета траекторий регионов в определенной форме аграрного сектора экономики используются следующие исходные данные муниципалитетов за конкретный год: численность занятых (чел.); объем производства (млн. руб.).

Уравнение прямой в прямоугольной системе координат имеет вид (рис.1):

$$
\mathrm{Y}_{\mathrm{x}}=\mathrm{a}_{0}+\mathrm{a}_{1} * \mathrm{X}
$$

где $\mathrm{a}_{0}$ - стартовое условие, млн. руб.;

$\mathrm{a}_{1}$ - коэффициент регрессии (прогрессии) - по- казывает, на сколько изменится величина результативного признака (объёмов производства, млн. руб.) при изменении значения факторного (численность работников, чел.) на единицу.

Визуально векторы развития регионов по углу наклона $\alpha$ можно сравнить при условии, что все точки рассеяния (муниципалитеты) каждого региона размещаются в прямоугольной системе координат, т.е. шкалы интервалов вариационных рядов по осям $\mathrm{X}$ и $\mathrm{Y}$ строятся с учетом максимальных и минимальных значений всех имеющихся исходных данных и одинаковы для всех регионов. В программе Region Vector определение угла наклона $\alpha$ траектории выполняется по специальной формуле, показывающей конкретное его числовое значение. Это необходимо в ситуации, когда пользователь увеличивает или уменьшает диаграмму рассеивания и изображение искажается. В этом случае показатель $\alpha$ остаётся неизменным. Применение формулы, встроенной в программу позволяет по числовому значению углов наклона траекторий сравнивать направленность развития территорий одного уровня управления даже при изменении шага интервала вариационных рядов.

Кроме того, можно визуально определять различия активности населения между регионами при сравнении изображений при печати или просмотре на мониторе. В этом случае диаграммы рассеивания и теоретические линии регрессии нескольких регионов (каждый в своей прямоугольной системе координат) одновременно выводятся на экран или на печать, при этом шаги интервалов вариационных рядов для исследуемых регионов ставятся одинаковые. Это позволяет сопоставить направленность развития регионов по траекториям, а также сравнивать распределения точек рассеяния и применить пространственно-координатный анализ объектов исследования, который представлен в предыдущей статье [7]. Следует отметить, что выбирать необходимо один из двух методов, т.к. они дают разные, но сопоставимые результаты по регионам.

\section{ОБСУЖДЕНИЕ РЕЗУЛЬТАТОВ}

Сущность ПО Region Vector заключается в выводе на монитор объективной информации в прямоугольной системе координат (ПСК), отражающей роль муниципалитетов в формировании направленности развития регионов в различных формах аграрного сектора экономики за определенный период: год, месяц, квартал. Количество ПСК меняется в зависимости от числа регионов, для которых выполняется алгоритм ПО. На оси 


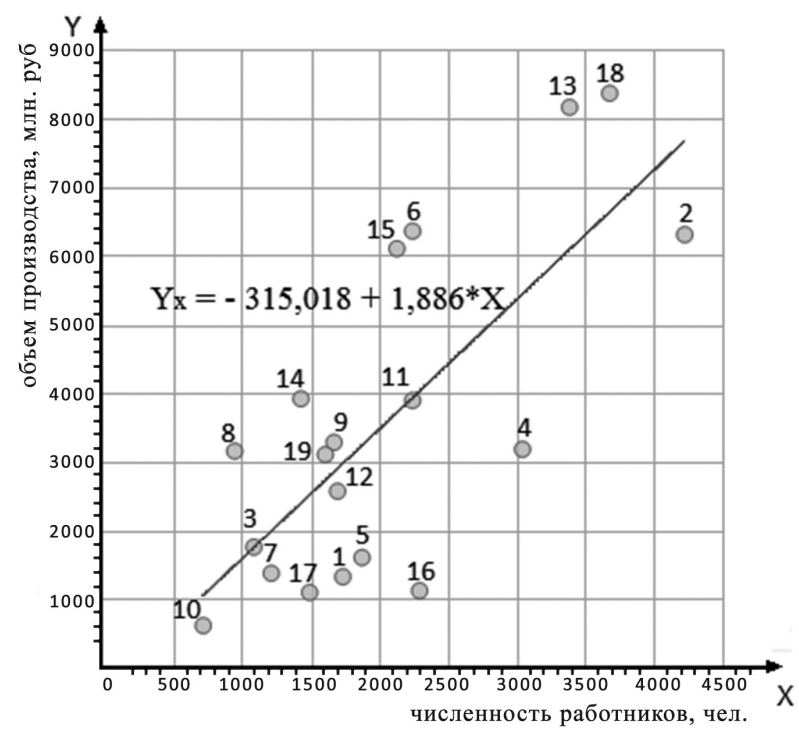

\author{
Информационное поле прямоугольной \\ системы координат \\ І.Показатели \\ ось X - численность работников, чел. \\ ось Y - объём произведенной продукции в \\ фактически действовавших ценах \\ (объём производства), млн. руб. \\ II. Шаги интервалов вариационных рядов \\ ось $\mathrm{X}=500$ работников \\ ось $\mathrm{Y}=1000$ млн. руб.
}

○ точки рассеяния (муниципальные районы Белгородской области)

теоретическая линия регресии $\mathrm{Y}_{\mathrm{x}}=\mathrm{a}_{0}+\mathrm{a}_{1} * \mathrm{X}$

(вектор активности населения на

сельхозпредприятиях системы

сельского расселения региона)

Муниципальные районы Белгородской области

1 Алексеевский

2 Белгородский

3 Борисовский

4 Валуйский

5 Вейделевский
6 Волоконовский

7 Грайворонский

8 Ивнянский

9 Корочанский

10 Красненский
11 Красногвардейский

12 Краснояружский

13 Новооскольский

14 Прохоровский 15 Ракитянский

*Шаги интервалов вариационных рядов определены с учётом максимальных и минимальных значений параметров базы данных показателей муниципальных образований Федеральной службы государственной статистики по всем регионам Центрального Черноземья [7]

[*The steps of the intervals of the variation series are determined taking into account the maximum and minimum values of the parameters of the database of indicators of municipalities of the Federal State Statistics Service for all regions of the Central Black Soil Region [7]]

Puc. 2. Линейная модель активности населения на сельхозпредприятиях системы сельского расселения Белгородской области за 2009 год в программе Region Vector

[Fig.2 Linear model of population activity in agricultural enterprises of the rural settlement system of the Belgorod region for 2009 in the Region Vector program]

$\mathrm{X}$ отмечается факторный признак - численность работников, чел., а на оси Ү - объем произведенной продукции, млн. руб. По этим показателям в прямоугольную систему координат наносятся точки рассеяния - муниципалитеты (рис. 2). Это могут быть как муниципальные районы, так и первичные муниципальные образования - сельские муниципалитеты (сельские поселения), деятельность которых регулируется федеральным законом от 6 октября 2003 года №131-Ф3 «Об общих принципах местного самоуправления в Российской федерации».

Для обеспечения выполнения задачи и технического результата ПО Region Vector выполняет следующие операции: 1) загрузка через текстовые файлы (*.txt) исходных данных о численности занятых (чел.) и объемах производства (млн. руб.) муниципалитетов по всем формам аграрного сектора экономики конкретной территории (региона); 2) автоматическое распределение исходных данных муниципалитетов в виде точек рассеяния в прямоугольных системах координат соответствующих регионов; 3) функция изменения шагов интервалов вариационных рядов по осям X и Y, которая обеспечивает возможность размещать и сравнивать распределения всех точек рассеяния (муниципалитетов) регионов; 4) вычисление параметров однофакторного уравнения линейной связи для отображения теоретических линий регрессии; 5) в результате появилась возможность определения направленности развития регионов на основе вычисления углов наклона $\alpha$ векторов развития (теоретических линий регрессии) по формуле 2, которые можно сравнить в конкретной форме аграрного сектора экономики за определенный период (год, месяц, квартал); 6) количественная оценка стартовых условий функционирования форм аграрного сектора экономики регионов по параметру а0 и начальной точке расположения вектора развития; 7) функция установки цвета точек рассеяния (муниципалитетов) для анализа территорий 
(муниципалитетов) отстающего и опережающего развития в условиях конкретного региона, что выполняется на основе визуальной оценки отклонений точек от вектора развития; 8) возможность сохранения и передачи баз исходных данных.

Практическое применение ПО Region Vector позволяет: а) визуально оценивать необходимую производительность труда для оптимизации производства сельхозпредприятий, крестьянских (фермерских) хозяйств и хозяйств населения по муниципальным районам в условиях конкретного региона, что выполняется на основе анализа отклонения точки рассеяния (муниципалитета) от теоретической линии регрессии; б) оперативно определять и сравнивать направленность развития форм аграрного сектора экономики регионов (по углу наклона $\alpha$ вектора развития); в) визуально оценивать степень диверсификации аграрной экономики по диапазону распределения точек рассеяния (муниципалитетов) относительно вектора развития, когда в районах с приблизительно одинаковой численностью занятых имеются существенные различия по объёмам производства сельхозпродукции; г) объективно определять муниципалитеты, для сохранения местного населения которых требуется разработка отдельных программ поддержки функционирования хозяйств населения, крестьянских (фермерских) хозяйств или развития несельскохозяйственных видов деятельности; д) выявлять районы проведения экспедиционных исследований, где возможно имеется необходимость увеличить или ограничить рост объемов производства крупных сельхозпредприятий, например, из-за резкого ухудшения экологической ситуации до устранения причин последствий для окружающей среды; е) спрогнозировать будущее экономическое состояние систем сельского расселения, если включить в модель целевые значения показателей по каждой форме аграрного сектора экономики [8].

ПО Region Vector было протестировано для исследований активности населения на двух уровнях управления: региональном и локальном (муниципальных районов).

На региональном уровне объектом исследования была выбрана территория Центрального Черноземья: Белгородская, Воронежская, Курская, Липецкая, Тамбовская области. Исходные данные включали показатели муниципальной статисти- ки о деятельности сельхозпредприятий за 2009 и 2014 годы по всем 119 муниципальным районам в составе пяти областей ЦЧР: численность работников, чел.; произведено продукции в фактически действовавших ценах (далее объём производства) сельхозпредприятий, млн. руб. [7].

На рисунках 2 и 3 показан результат применения алгоритма по данным за 2009 год. В 2014 году по сравнению с 2009 в прямоугольных системах координат областей Центрального Черноземья отразились существенные изменения в ряде муниципальных районов, особенно в Белгородской области. В Курской и Тамбовской областях некоторые муниципалитеты (точки рассеяния) отделились от основной группы, относительно рядом расположенной с теоретической линией регрессии, что отразилось на различиях в их углах наклона. Таким образом, направленность развития регионов в аграрном секторе экономики различается и постепенно меняется, что связано с диверсификацией производства, выходом некоторых муниципальных районов на новый уровень производительности труда. Подробное описание и графические материалы тестов применения программы можно увидеть в предыдущей статье [7].

Кроме того, оценка возможностей применения алгоритма проводилась на примере пяти муниципальных районов Воронежской области (рис. 4): Новохопёрский, Таловский, Кантемировский, Россошанский, Новоусманский. Исходные данные паспортов сельских поселений за 2004 и 2009 годы о численности работников сельхозпредприятий (чел.) и объемах произведенной продукции (тыс. руб.) были распределены в таблицы по каждому муниципальному району отдельно. После чего строились диаграммы рассеяния. Затем аналогичным образом были систематизированы сведения о занятых и объемах производства личных подсобных хозяйств этих же районов.

Статистически значимые результаты корреляционного анализа стали основанием для построения диаграмм рассеяния и выполнения регрессионного анализа по муниципальным районам. Анализ распределений и траекторий подтвердил, что в условиях снижения занятости на сельхозпредприятиях за период 20042009 годов возросла активность населения в личных подсобных хозяйствах, что обеспечило устойчивость системы расселения. Вместе с тем интенсивность этих процессов различается в зависимости от географического положения муниципальных районов [5]. 

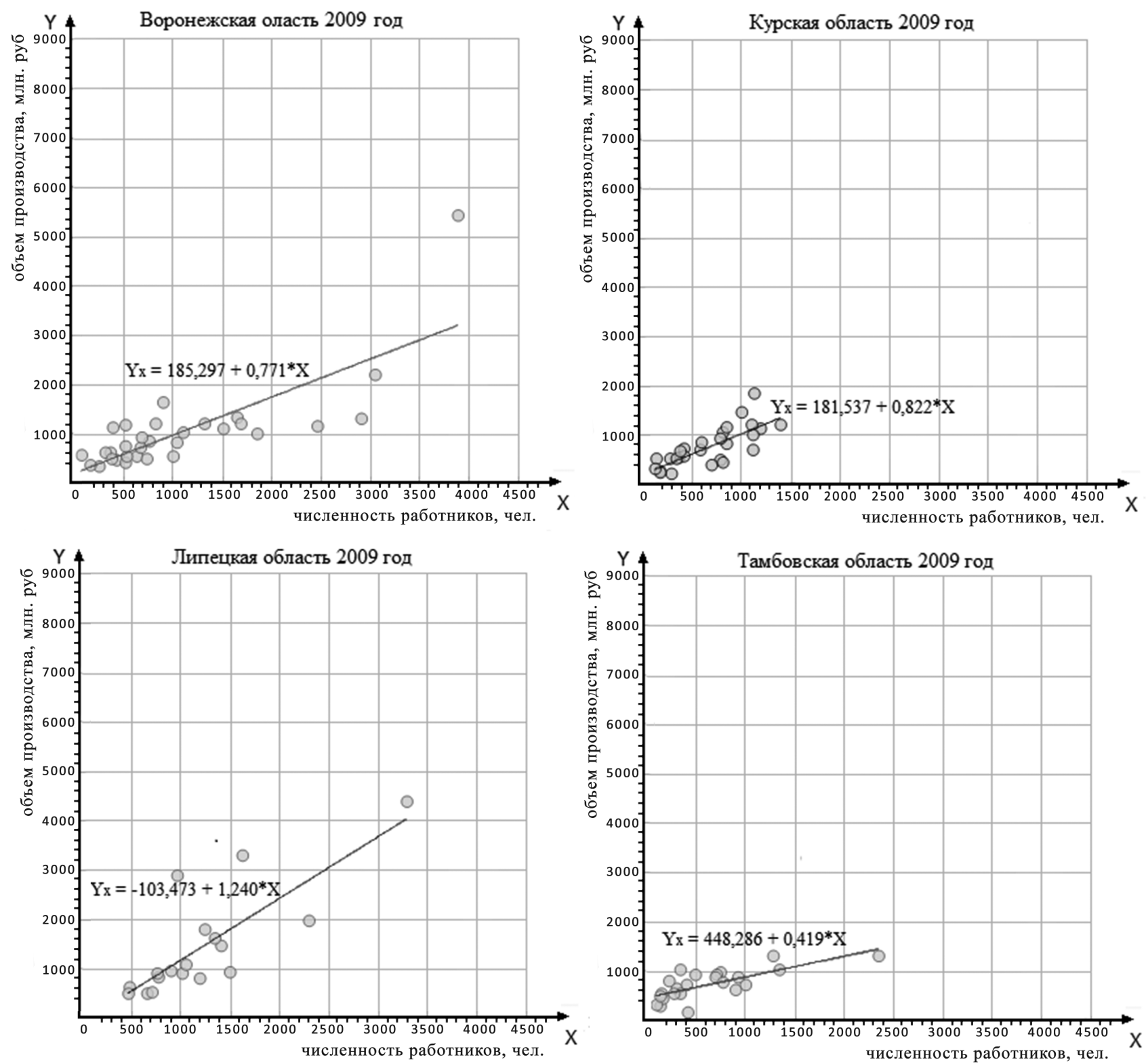

Puc.3. Применение ПО Region Vector для построения моделей активности населения в аграрном секторе экономики на примере сельхозпредприятий систем сельского расселения Воронежской, Курской, Липецкй, Тамбовской областей за 2009 год

[Fig. 3. Application of the Region Vector software for building models of population activity in the agricultural sector of the economy on the example of agricultural enterprises in the rural settlement systems of the Voronezh, Kursk, Lipetsk, and Tambov regions in 2009]

\section{ЗАКЛЮЧЕНИЕ}

Программу Region Vector можно применять не только для анализа регионов, но также для любых территорий одного уровня управления, например, муниципальных районов, где исходные данные представляют собой показатели сельских муниципалитетов. Это позволяет: 1) выполнять сравнительный пространственно-координатный анализ распределений точек рассеяния по территориям относительно теоретических линий регрессии (определение числа объектов исследования выше и ниже траектории, выявлять муниципалитеты на значительном отклонении от линии, которая отражает среднюю активность, производительность труда по региону); 2) определять территории (муниципалитеты) первоочередного развития, для которых в первую очередь необходимо разработать программы поддержки хозяйств населения, фермерских хозяйств, сельхозпредприятий; 3) оценивать различия в на- 

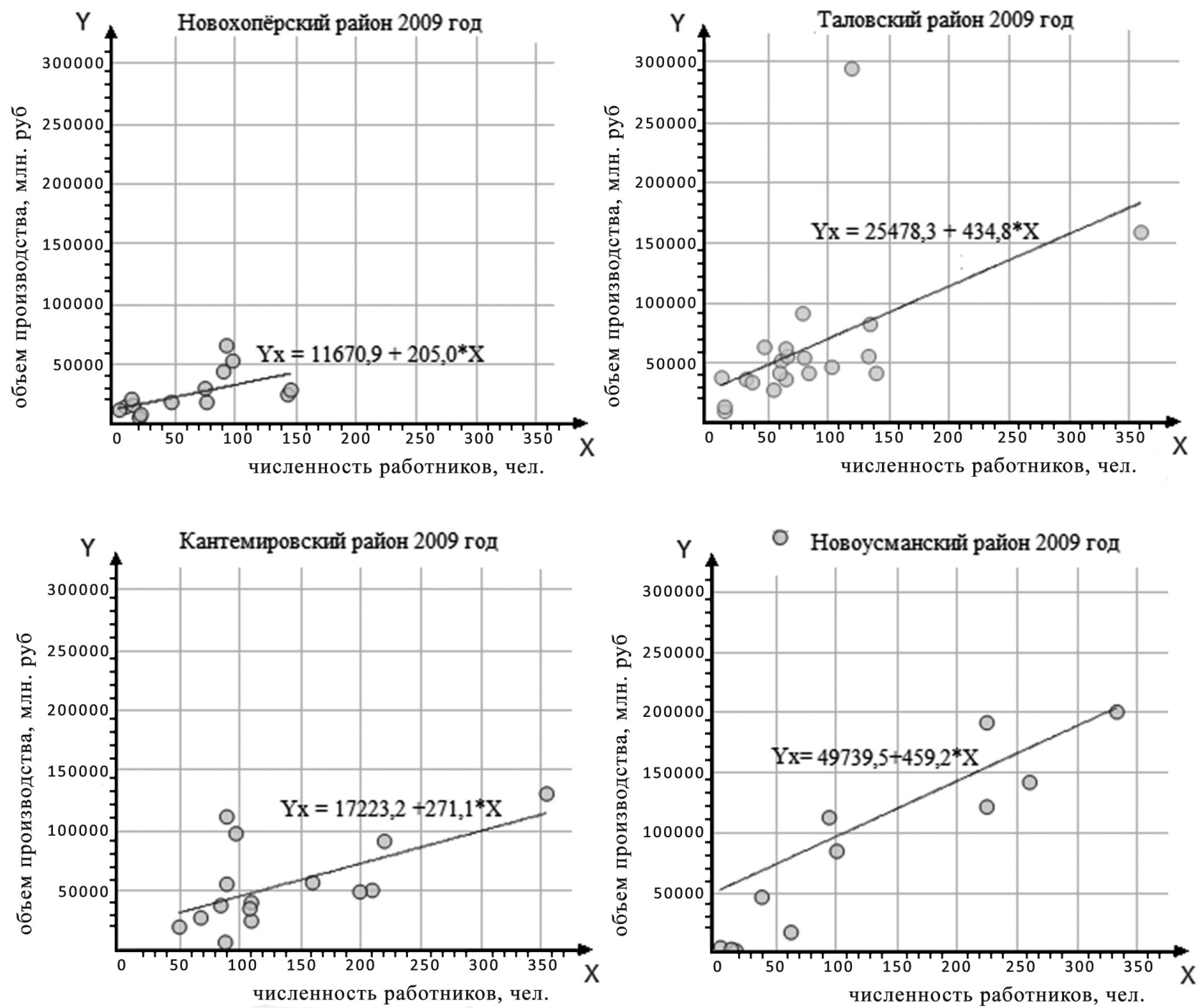

Puc.4. Применение программы Region Vector для построения моделей активности населения в аграрном секторе экономики на примере сельхозпредприятий систем сельского расселения четырех муниципальных районов Воронежской области за 2009 год

[Fig. 4. Application of the Region Vector program for building models of population activity in the agricultural sector of the economy on the example of agricultural enterprises rural settlement systems of four municipal districts of the Voronezh region in 2009]

правленности развития форм аграрного сектора экономики между регионами или муниципальными районами по углу наклона $\alpha$ траектории.

Программное обеспечение Region Vector дает возможность корректировать разработку схем развития и размещения производительных сил по регионам для обеспечения равномерного развития аграрной экономики муниципалитетов с учетом их возможностей. Разработка представленной информационной технологии не ограничивается описанными выше показателями. Мы продолжаем совершенствовать программное обеспечение для анализа систем сельского расселения.

\section{СПИСОК ЛИТЕРАТУРЫ}

1. Архипов Ю. Р. Оценка устойчивости развития систем расселения муниципальных районов (на примере Чувашии) // Материаль Первой международной научно-практической конференции «Муниципальные образования современных регионов: проблемы исследования, развития и управления в условиях геоэкономической и политической нестабильности». Воронеж, 2016, c. 14-17.

2. Воронин В. В., Кочуров Б. И., Поросенков Ю. В. Социильная география Российской Федерации. Самара: ООО «СамЛюксПринт», 2015, 308 с.

3. Дроздова Е. М. Корреляционно-регрессионный анализ показателей сельскохозяйственного производства Приморского края // Дискуссия, 2013, № 11, с. 55-59. 
4. Нестеров Ю. А., Нгуен Ч. Х. Геоинформационный анализ системы расселения населения Центрально-Черноземных областей // Материаль Первой международной научно-практической конференции «Муниципальные образования современных регионов: проблемь исследования, развития и управления в условиях геоэкономической и политической нестабильности». Воронеж, 2016, с. 221-225.

5. Носонов А. М. Моделирование в социально-экономической географии // Псковский регионологический журнал, 2014, № 19, с. 3-15.

6. Овсянников А. С. Поросенков Ю. В. Географическое исследование современных процессов сельского расселения методом математического моделирования // Вестник Воронежского государственного университета. Серия: География. Геоэкология, 2013, № 2, c. $56-66$.

7. Попкова Л. И., Овсянников А. С. Возможности экономико-географического исследования функций систем сельского расселения методом математического моделирования // Вестник Воронежского государственного университета. Серия: География. Геоэкология, 2017, № 4, с. 48-59.

8. Попкова Л. И., Овсянников А. С. Основы пространственно-координатного анализа активности населения в аграрном секторе экономики // Mатериаль научно-практической конференции «Стратегия развития приграничных территорий: традиции и инновациии». Курск, 2018, с. 70-79.

9. Пронченко Л. В. Корреляционно-регрессионная модель зависимости объема выпуска продукции и факторов воздействующих на него // Becmник РГАЗУ, 2012, ч.2. Доступно: http://edu.rgazu.ru/ file.php/1/vestnik_rgazu/index.html (дата обращения: 10.02.2020)

10. Филимоненко И. В. Моделирование зависимости роста ВВП от изменения структуры занятости в экономике РФ // Вестник НГУ. Серия: Социально-экономические науки, 2011, т. 11, вып. 1, с. 16-25.

Конфликт интересов: Авторы декларируют отсутствие явных и потенциальных конфликтов интересов, связанных с публикацией настоящей статьи.

Поступила в редакциию 20.02.2020 Принята к публикации 02.03.2021

UDC 711.13 (470.324)

ISSN 1609-0683

DOI: https://doi.org/10.17308/geo.2021.1/3251

\title{
Region Vector - Software for Analyzing the Activity of the Population in the Agricultural Sector of the Economy
}

\author{
L. I. Popkova ${ }^{1}$, A. S. Ovsyannikov ${ }^{2}$ 四 \\ ${ }^{1}$ Kursk State University, Russian Federation \\ (33, Radishcheva St., Kursk, 305000) \\ ${ }^{2}$ Limited Liability Company "PPF Life Insurance", Russian Federation \\ (17A, Kosmonavtov St., Voronezh, 394038)
}

\begin{abstract}
Purpose: The purpose is to create a computer programme based on the methods of mathematical statistics. It will show the vectors of development of rural settlement systems of regions and municipal districts in the agricultural sector of the economy.

The information base was the materials of the territorial bodies of the Federal State Statistics Service of the Belgorod, Voronezh, Kursk, Lipetsk, and Tambov regions.

Methods. The solution of the main purpose of the work was achieved by using methods of correlation and regression analysis. Vectors of development (theoretical regression lines) of each region were modeled in a rectangular coordinate system. The use of spatial-coordinate analysis of research objects made it possible to visually compare the direction of regional development by the angle of inclination of the trajectories as well as
\end{abstract}

(C) Popkova L.I., Ovsyannikov A.S., 2021

凶 Artem S. Ovsyannikov, e-mail: artem_ovsyannikov@list.ru

(c) (i) The content is available under Creative Commons Attribution 4.0 License.

Вестник ВГУ, Серия: География. Геоэкология, 2021, № 1, 3-13 


\section{L.I. Popkova, A.S. Ovsyannikov}

to determine municipalities lagging behind in labour productivity. Results and discussions. Quantitative and visual assessment of changes in the direction of development of agricultural enterprises of five regions of the Central Black Soil Region for the period 2009-2014 was done. On this basis, a computer programme has been created that allows you to objectively assess the development trajectories of agricultural enterprises, farms and farms of the population of the regions.

Conclusions. Using the computer programme and spatial-coordinate analysis of models (objects of study) will give an advantage to management institutions in assessing the situation and responding to negative changes in labour productivity in the agricultural sector of the economy of municipalities.

Key words: region, employed population, municipalities, correlation and regression analysis, spatialcoordinate analysis, $\alpha$ of the vector of development.

For citation: Popkova L. I., Ovsyannikov A. S. Region Vector - Software for Analyzing the Activity of the Population in the Agricultural Sector of the Economy. Vestnik Voronezskogo gosudarstvennogo universiteta. Seria: Geografia. Geoekologia, 2021, no. 1, pp. 3-13. (In Russ.) DOI: https://doi.org/10.17308/geo.2021.1/3251

\section{REFERENCES}

1. Arkhipov Yu. R. Otsenka ustoychivosti razvitiya sistem rasseleniya munitsipal'nykh rayonov (na primere Chuvashii) [Assessment of the sustainability of the development of settlement systems in municipal areas (on the example of Chuvashia)]. Materialy Pervoy mezhdunarodnoy nauchno-prakticheskoy konferentsii "Munitsipal'nye obrazovaniya sovremennykh regionov: problemy issledovaniya, razvitiya i upravleniya $v$ usloviyakh geoekonomicheskoy i politicheskoy nestabil'nosti». Voronezh, 2016, pp. 14-17. (In Russ.)

2. Voronin V. V., Kochurov B. I., Porosenkov Yu. V. Sotsial'naya geografiya Rossiyskoy Federatsii [Social geography of the Russian Federation]. Samara: OOO «SamLyuksPrint», 2015, 308 p. (In Russ.)

3. Drozdova E. M. Korrelyatsionno-regressionnyy analiz pokazateley sel'skokhozyaystvennogo proizvodstva Primorskogo kraya [Correlation-regression analysis of indicators of agricultural production in Primorsky Krai]. Diskussiya, 2013, no 11, pp. 55-59. (In Russ.)

4. Nesterov Yu. A., Nguen Ch. Kh. Geoinformatsionnyy analiz sistemy rasseleniya naseleniya Tsentral'no-Chernozemnykh oblastey [Geoinformation analysis of the population settlement system of the Central Black Earth regions]. Materialy Pervoy mezhdunarodnoy nauchno-prakticheskoy konferentsii: "Munitsipal'nye obrazovaniya sovremennykh regionov: problemy issledovaniya, razvitiya i upravleniya $v$ usloviyakh geoekonomicheskoy i politicheskoy nestabil'nosti». Voronezh, 2016, pp. 221-225. (In Russ.)

5. Nosonov A. M. Modelirovanie v sotsial'no-ekonomicheskoy geografii [Modeling in socio-economic geography]. Pskovskiy regionologicheskiy zhurnal, 2014, no 19, pp. 3-15. (In Russ.)

6. Ovsyannikov A. S. Porosenkov Yu. V. Geograficheskoe issledovanie sovremennykh protsessov sel'skogo rasseleniya metodom matematicheskogo modelirovaniya [Geographic study of modern processes of rural settlement by the method of mathematical modeling]. Vestnik Voronezhskogo gosudarstvennogo universiteta. Seria: Geografia. Geoekologia, 2013, no 2, pp. 56-66. (In Russ.)

7. Popkova L. I., Ovsyannikov A. S. Vozmozhnosti ekonomiko-geograficheskogo issledovaniya funktsiy sistem sel'skogo rasseleniya metodom matematicheskogo modelirovaniya [Possibilities of economic and geographical research of the functions of rural settlement systems by the method of mathematical modeling]. Vestnik Voronezhskogo gosudarstvennogo universiteta. Seria: Geografia. Geoekologia, 2017, no 4, pp. 48-59. (In Russ.)

8. Popkova L. I., Ovsyannikov A. S. Osnovy prostranstvenno-koordinatnogo analiza aktivnosti naseleniya $\mathrm{V}$ agrarnom sektore ekonomiki [Basics of spatial-coordinate analysis of population activity in the agricultural sector of the economy]. Materialy nauchno-prakticheskoy konferentsii «Strategiya razvitiya prigranichnykh territoriy: traditsii i innovatsii». Kursk, 2018, pp. 70-79. (In Russ.)

9. Pronchenko L. V. Korrelyatsionno-regressionnaya model' zavisimosti ob"ema vypuska produktsii i faktorov vozdeystvuyushchikh na nego [Correlation-regression model of the dependence of the volume of output and the factors affecting it]. Vestnik $R G A Z U, 2012$, part 2. Available at: http://edu.rgazu.ru/file.php/1/vestnik_rgazu/index. html (accessed 10.02.2020). (In Russ.)

10. Filimonenko I. V. Modelirovanie zavisimosti rosta VVP ot izmeneniya struktury zanyatosti $\mathrm{v}$ ekonomike RF [Modeling the dependence of GDP growth on changes in the structure of employment in the Russian economy]. Vestnik NGU. Seria: Sotsial'no-ekonomicheskie nauki, 2011, vol. 11, v. 1, pp. 16-25. (In Russ.)

Conflict of interests: The authors declare no information of obvious and potential conflicts of interest related to the publication of this article.

Received 20.02.2020 Accepted 02.03.2021 
Попкова Людмила Ивановна

доктор географических наук, профессор кафедры географии естественно-географического факультета Курского государственного университета, г. Курск, Российская Федерация, ORCID: 0000-0003-3595-7235, e-mail: geopoli@mail.ru

Овсянников Артем Сергеевич

кандидат географических наук, финансовый консультант ООО «ППФ Страхование Жизни», г. Курск, Российская Федерация, ORCID: 0000-00031985-5124, e-mail: artem_ovsyannikov@list.ru
Lyudmila I. Popkova

Dr. Sci. (Geogr.), Professor of the Department of Geography of Natural-Geographical Faculty, Kursk State University, Kursk, Russian Federation, ORCID: 0000-0003-35957235, e-mail: geopoli@mail.ru

Artem S. Ovsyannikov

Cand. Sci. (Geogr.), financial consultant of the limited liability company "PPF Life Insurance", Voronezh, Russian Federation, ORCID: 0000-0003-1985-5124, e-mail: artem_ovsyannikov@mail.ru 